\title{
A Study on the Validation of Green Supply Chain Performance Measures in the Automotive Industry
}

\author{
Ezutah Udoncy Olugu and Kuan Yew Wong \\ Department of Manufacturing and Industrial Engineering, Faculty of Mechanical Engineering, \\ Universiti Teknologi Malaysia, Malaysia
}

\begin{abstract}
This study was aimed at establishing the validity of the measures and metrics for automobile green supply chain performance measurement. The study involved statistical tests using 16 measures and 72 corresponding metrics. These statistical tests include exploratory factor analysis to investigate the construct validity of the measures and their metrics, a confirmatory factor analysis to test the model fitness and a multiple regression analysis to test the criterion validity of the measures. From the results obtained, the validity of the measures and their corresponding metrics has been established. The paper culminated with recommendations for further studies.
\end{abstract}

Keywords: Green supply chain; performance measurement; validity; exploratory factor analysis; confirmatory factor analysis.

\section{Introduction}

Environmental related issues have been receiving a lot of attention in the past few decades. This is not unconnected with recent natural threats accompanying environmental degradation in various parts of the globe. Governments, nongovernmental organizations and private corporations have been adopting various strategies to assuage the level of antienvironmental practices in the areas of waste disposal, air emission, use of natural resources, etc. Some of these measures include regulations, environmental legislations, and environmental bilateral relations etc. It has been observed that an effective and efficient environmental stewardship cannot be achieved in isolation. This is sequel to the fact that manufacturing has become an interorganizational operation in which firms either source or supply globally. It has been observed that an automobile manufacturer has about 300 suppliers (Turnbull et al, 1992). Therefore, to achieve a formidable environmental stewardship and management in the automotive industry, there is a need to involve all the parties involved in the manufacturing process. One important strategy adopted by manufacturers to achieve this fit is green supply chain management (GSCM). Practitioners and researchers have all attested to the efficiency and effectiveness of GSCM in achieving organizational environmental stewardship. Since performance measurement has been identified as a means of achieving an efficient GSCM (Hervani et al, 2005), the objective of this study is to validate the performance measures for GSCM in the automotive industry. The measures and their corresponding metrics have been adopted from an earlier study in Olugu et al (2010a).

Copyright (C) 2011 Ezutah Udoncy Olugu and Kuan Yew Wong. This is an open access article distributed under the Creative Commons Attribution License unported 3.0, which permits unrestricted use, distribution, and reproduction in any medium, provided that original work is properly cited. Contact Author: Ezutah Udoncy Olugu e-maill: goi.chai.lee@curtin.edu.my 
The paper begins with an introduction into environmental management and GSCM. This is followed by a description of GSCM, its performance measurement, and the adopted measures and metrics in section 2 . Section 3 contains the validation process, results and discussions. Finally, conclusions and recommendations for further study are presented in section 4 .

\section{Green Supply Chain Management (GSCM)}

GSCM has been described as encompassing green purchasing, green manufacturing and material management, green distribution and marketing, and finally reverse logistics (Hervani et al, 2005; Linton et al, 2007; Sarkis, 2003; Wycherley, 1999; Zhu and Sarkis, 2006). It was further described as an environmental improvement strategy and operational initiative which organizations adopt in order to address environmental issues within their supply chains (Rao and Holt, 2005). This is in line with the explanation given in Schultmann et al (2004) and Vachon and Klassen (2008) that suppliers, manufacturers and customers should work together towards the reduction of environmental impact from production processes and their ensuing products. Hence, GSCM involves the minimization of an organization's total environmental impact from start to finish of the supply chain and also from beginning to end of the product life cycle (Beamon, 1999; Green et al, 1998; Olugu et al, 2010b; Zhu and Sarkis, 2004).

\section{Supply Chain Performance Measurement}

As supply chain focuses on the process management within and beyond organizational boundaries, measuring its performance is necessary for control and improvement purposes (Gunasekaran et al, 2001; Kranjnc et al, 2007; Liang et al, 2006; Neely et al, 2005; Stewart, 1995). It has been pointed out that inadequate performance measures is one of the major obstacles to efficient SCM performance measurement (Lai et al, 2002; Morgan, 2004). The measures and metrics which are used in this study as adopted from Olugu et al (2010a) are described here under. The measures are divided into 2 sets based on a conceptual framework in Olugu et al (2010b). The first is for the forward chain and the other is for the reverse chain. The forward chain measures and their metrics are as follows:

- Greening Cost (GC): This involves the overall cost incurred by a company in making sure that its operations are environmentally sustainable. The metrics under this measure include cost associated with environmental compliance, energy consumption cost, environmentally friendly materials cost, and green cost per revenue.

- Management Commitment (MC): This involves the overall management effort and initiatives in GSCM. It is evaluated using metrics such as level of management effort to motivate employees, availability of environmental evaluation schemes, availability of environmental auditing systems, availability of mission statements on environmental sustainability, number of environmental management initiatives, level of management effort to enlighten customers on sustainability, availability of environmental reward systems and level of management effort to motivate suppliers.

- Level of Process Management (LPM): This considers all process modifications aimed at reducing environmental degradation. It covers metrics such as availability of process optimization for waste reduction, level of spillage, leakage and pollution control, level of waste generated during production, quantity of utilities used, and number of violations of environmental regulations.

- Product Characteristics (PC): This measures the composition of the automobiles. This is evaluated as level of recycled materials in products, level of products to be disposed to land-fills, availability of eco-labeling, level of biodegradable contents in products, level of applications of design-for- 
assembly in products and level of market shares controlled by products.

- Quality (QUAL): This is the overall standard of the products. It is assessed using metrics such as percentage decrease in customer dissatisfaction, percentage decrease in delivery unreliability, percentage decrease in scrap and rework, and availability of green product warranty.

- Responsiveness (RESP): It measures the rate of response of the chain to GSCM. Metrics such as percentage decrease in order lead time, percentage decrease in product development cycle time, percentage decrease in manufacturing lead time, percentage decrease in total supply chain cycle time, and percentage increase in on-time delivery are used for its evaluation.

- Flexibility (FLEX): This measures the ease with which the chain adapts to GSCM. This includes metrics such as percentage increase in demand flexibility, percentage increase in delivery flexibility, percentage increase in production flexibility and percentage increase in fill rate.

- Traditional Supply Chain Cost (TSCC): This measures the effect of GSCM on the regular SCM cost. Metrics under this measure are percentage decrease in total supply chain cost, percentage decrease in delivery cost, percentage decrease in inventory cost, percentage decrease in information sharing cost and percentage decrease in ordering cost.

- $\quad$ Supplier Commitment (SC): This implies the extent of suppliers' devotion to GSCM. Metrics here include level of supplier environmental certification, level of supplier performance on sustainability, number of supplier initiatives on environmental management, level of disclosure of environmental initiatives to the public and level of supplier preprocessing of raw materials.
- Customer Perspective (CP): This involves consideration on the customers' view towards GSCM. Metrics under this measure are level of customer interest in green products, level of customer satisfaction from green products and level of customer dissemination of green information.

The measures for the reverse chain performance measurement are listed in the ensuing paragraphs.

- $\quad$ Recycling Cost (RC): It is measured as the cost associated with recycling and recovery of end-of-life vehicles (ELVs). Under these are metrics such as cost associated with returning ELVs, cost associated with processing recyclables, cost of sorting and segregating recyclables, and cost of disposing hazardous and unprocessed waste.

- Material Features (MF): This measures the components of the ELVs. It includes level of waste generated, ratio of recycled materials to recyclable materials, and material recovery time.

- Management Commitment (MC): This measures the management's effort in the reverse logistics process. This is evaluated with metrics such as level of motivation to customers on returning their ELVs, availability of standard operating procedures for collecting ELVs, availability of collection centers for ELVs, and availability of waste management schemes.

- $\quad$ Recycling Efficiency (RE): It measures the effectiveness of the recycling process. This includes percentage decrease in recycling time, availability of recycling standards, availability of standard operating procedures, percentage decrease in utility usage during recycling, efficiency of shredders and dismantlers, and percentage reduction in emission and waste generated.

- Customer Involvement (CI): This evaluates the willingness and 
cooperation from users. It is evaluated with the following metrics: level of customer cooperation in returning ELVs, level of customer-to-customer dissemination of information, and level of understanding of the greening process by customers.

- $\quad$ Supplier Commitment (SC): It evaluates suppliers' initiatives in the reverse logistics process. The metrics here include extent of return delivery from suppliers to manufacturers, certification system for suppliers in recycling and number of supplier initiatives in reverse logistics.

\section{Validation of Measures}

A questionnaire survey has been conducted amongst academics and practitioners to examine the importance and applicability of the measures and their metrics in GSCM performance measurement. This is in addition to the survey that was carried out earlier in Olugu et al (2010a). Additional 87 respondents completed and returned the questionnaires bringing the total respondents to 120 . The academics were selected from SCOPUS directory and practitioners were selected based on their position and experience in the automotive industry.

\section{Principal Component Analysis}

In order to assess the construct validity of the measures, and to evaluate their underlying structure which comprised 49 metrics for the forward chain and 23 for the reverse chain, principle component analysis using varimax rotation was conducted using SPSS software. 10 factors with Eigenvalues above 1.0 were returned for the forward chain. The rule of thumb is that the number of Eigenvalues greater than 1 is the number of factors (Brown, 2006). As presented in Table 1, 10 Eigenvalues greater than 1 were obtained. 
Table 1. Principal Factor Analysis (Forward Chain-Importance)

\begin{tabular}{|c|c|c|c|c|c|c|c|c|c|c|}
\hline & \multicolumn{10}{|c|}{ FACTORS } \\
\hline & $F 1$ & $F 2$ & F3 & $F 4$ & $F 5$ & F6 & $F 7$ & $F 8$ & F9 & F10 \\
\hline \% Variance & 16.6 & 11.6 & 11.13 & 8.14 & 5.9 & 5.6 & 4.46 & 3.94 & 3.6 & 3.4 \\
\hline Eigenvalue & 6.57 & 4.53 & 4.43 & 3.18 & 2.3 & 1.97 & 1.74 & 1.54 & 1.39 & 1.12 \\
\hline \multicolumn{11}{|l|}{ GC } \\
\hline MF11 & .68 & -.22 & -.12 & .28 & -.14 & -.24 & -.02 & .15 & -.14 & .08 \\
\hline MF12 & .75 & -.19 & .26 & .18 & -.29 & -.11 & .04 & .11 & .25 & .23 \\
\hline MF13 & .70 & .28 & .17 & .41 & .05 & .19 & .26 & .37 & .39 & .16 \\
\hline MF14 & .67 & .44 & -.24 & .24 & .12 & .11 & .11 & .21 & -.17 & .14 \\
\hline \multicolumn{11}{|l|}{ CP } \\
\hline MF21 & .08 & .63 & .05 & .24 & -.19 & .14 & -.25 & .23 & .12 & -.19 \\
\hline MF22 & .09 & .69 & .07 & .04 & .12 & -.15 & .29 & .06 & .26 & .29 \\
\hline MF23 & .16 & .73 & .22 & .34 & -03 & .25 & .24 & .41 & .21 & -.22 \\
\hline \multicolumn{11}{|l|}{ LPM } \\
\hline MF31 & -.31 & .26 & .82 & -.03 & .23 & -.22 & .07 & -.03 & -.07 & .12 \\
\hline MF32 & .24 & -.09 & .76 & .37 & -.13 & .24 & .02 & .23 & .04 & -.02 \\
\hline MF33 & -.14 & -.27 & .87 & .01 & -.30 & -.04 & .19 & .34 & .27 & -.04 \\
\hline MF34 & .40 & -.29 & .66 & .08 & -.05 & .40 & .05 & .36 & -.23 & .09 \\
\hline MF35 & .32 & .33 & .53 & .16 & .35 & .32 & .24 & .31 & .17 & .05 \\
\hline \multicolumn{11}{|l|}{ PC } \\
\hline MF41 & .03 & -.27 & .17 & .59 & -14 & .36 & -.28 & .20 & -.36 & .30 \\
\hline MF42 & .17 & .36 & .08 & .72 & .28 & -.04 & .42 & -.07 & .30 & -.15 \\
\hline MF43 & .07 & .04 & .16 & .65 & .19 & -.01 & -.06 & .21 & .06 & -.19 \\
\hline MF44 & .30 & .43 & .35 & .52 & .38 & .04 & .37 & -.07 & .25 & -.36 \\
\hline MF45 & -.16 & .03 & .25 & .78 & -08 & .03 & .18 & .09 & .39 & .32 \\
\hline MF46 & .02 & .28 & .12 & .68 & -05 & .03 & .15 & .27 & .01 & .31 \\
\hline \multicolumn{11}{|l|}{ MC } \\
\hline MF51 & .21 & .03 & .44 & -.08 & .64 & .13 & .35 & -.12 & .27 & .01 \\
\hline MF52 & .41 & .04 & .27 & .32 & .62 & .37 & .26 & .36 & .24 & .40 \\
\hline MF53 & .20 & -.08 & .32 & .05 & .75 & .33 & .08 & .16 & .02 & .10 \\
\hline MF54 & .40 & .05 & .15 & .03 & .71 & .27 & .39 & .01 & .24 & .18 \\
\hline MF55 & .42 & .13 & .43 & .33 & .63 & .03 & .16 & .42 & -.07 & .04 \\
\hline MF56 & .26 & .35 & .26 & .08 & .55 & .12 & .05 & .06 & .12 & -.02 \\
\hline MF57 & .15 & -.12 & .36 & .18 & .58 & .42 & .06 & .11 & .21 & .21 \\
\hline MF58 & .18 & .28 & .14 & -.12 & .69 & .10 & .27 & -.09 & .34 & .45 \\
\hline \multicolumn{11}{|l|}{ SC } \\
\hline MF61 & .07 & .12 & -.15 & .07 & .19 & .60 & .11 & .05 & .24 & .16 \\
\hline MF62 & .28 & -.25 & .21 & .21 & -17 & .59 & -.31 & .30 & -.19 & -.28 \\
\hline MF63 & .24 & .15 & .27 & .34 & -15 & .55 & .25 & .21 & .10 & .18 \\
\hline MF64 & .14 & .21 & -.34 & .20 & .17 & .61 & .32 & -.17 & .17 & .12 \\
\hline MF65 & .21 & .11 & .29 & .36 & -18 & .72 & .16 & .13 & .10 & .23 \\
\hline \multicolumn{11}{|l|}{ T SCC } \\
\hline MF71 & .09 & .11 & .06 & .15 & -06 & .09 & .56 & .06 & -.22 & .17 \\
\hline MF72 & .02 & -.13 & .11 & .29 & -04 & .19 & .63 & .13 & .09 & .05 \\
\hline MF73 & .28 & .26 & .32 & .21 & .21 & .31 & .61 & .15 & -.13 & -.09 \\
\hline MF74 & .26 & -.01 & .36 & .11 & .14 & .33 & .79 & .20 & -.12 & .05 \\
\hline MF75 & .21 & -.08 & .08 & .24 & -02 & .27 & .68 & .03 & -.18 & -.23 \\
\hline \multicolumn{11}{|l|}{ RESP } \\
\hline MF81 & -.08 & .17 & .19 & -.02 & .33 & .04 & .20 & .57 & .21 & .14 \\
\hline MF82 & -.14 & .02 & -.09 & .25 & -.17 & -.24 & -.33 & .54 & .21 & .17 \\
\hline MF83 & .19 & .06 & .32 & .17 & .10 & .03 & -.08 & .63 & .24 & .28 \\
\hline MF84 & -.16 & -.08 & -.26 & -.05 & -.30 & -.22 & -.25 & .65 & -.13 & -.12 \\
\hline MF85 & .04 & -.09 & -.09 & -.06 & -15 & -.24 & .04 & .58 & -.09 & .05 \\
\hline \multicolumn{11}{|l|}{ QUAL } \\
\hline MF91 & .25 & .26 & .05 & .05 & .29 & .20 & .27 & .17 & .77 & -.19 \\
\hline MF92 & .14 & .04 & .10 & .13 & .19 & .06 & .30 & -.08 & .68 & .14 \\
\hline MF93 & .09 & .29 & .07 & .04 & .12 & -.11 & .24 & .02 & .81 & .25 \\
\hline MF94 & .16 & -.22 & .34 & .34 & -.03 & .41 & .24 & .14 & .63 & .18 \\
\hline \multicolumn{11}{|l|}{ FLEX } \\
\hline MF101 & -.12 & -.27 & .03 & .01 & -30 & -.04 & .19 & .34 & .19 & .72 \\
\hline MF102 & .21 & .29 & .28 & .08 & -.05 & .20 & .05 & .36 & -.08 & .57 \\
\hline MF103 & .24 & -.09 & .02 & .37 & -.13 & .24 & .02 & .23 & -.05 & .63 \\
\hline MF104 & .08 & -.19 & .05 & .24 & -19 & .14 & -.24 & .24 & -.18 & .66 \\
\hline
\end{tabular}


This goes to validate the construct of the measures. From the result of the rotation, the factors which are greening cost, customer perspective, level of process management, product characteristics, management commitment, supplier commitment, traditional supply chain cost, responsiveness, quality and flexibility have the following variances explained: $16.6 \%$, $11.6 \%, 11.13 \%, 8.14 \%, 5.9 \%, 5.6 \%, 4.46 \%$, $3.94 \%, 3.6 \%$ and $3.4 \%$ respectively. The items and their loadings for the rotated factors are also given in Table 1.

Similar analysis was conducted for the reverse chain measures. The number of items involved was 23 and 6 factors with eigenvalues above 1.0 were returned. The items indexed impressively to the 6 major factors. The variances explained by each of the factors (recycling cost, customer involvement, material features, management commitment, supplier commitment and recycling efficiency) are $18.7 \%, 12 \%, 10.9 \%, 9.3 \%, 7.6 \%$, and $7.1 \%$ respectively. These are shown in Table 2. These factors accounted for the following eigenvalues: $4.31,2.75,2.51,2.14,1.75$, and 1.4 accordingly. This analysis proved that the construct validity of the measures is established in terms of their importance. Likewise, it is shown in Tables 3 and 4 that the construct validity of the measures in terms of applicability is established.

Table 2.Principal Factor Analysis (Reverse Chain-Importance)

\begin{tabular}{|c|c|c|c|c|c|c|}
\hline & \multicolumn{6}{|c|}{ Factors } \\
\hline & F1 & $F 2$ & F3 & $F 4$ & F5 & F6 \\
\hline \% Variance & 18.7 & 12 & 10.9 & 9.3 & 7.6 & 7.11 \\
\hline Eigenvalue & 4.31 & 2.75 & 2.51 & 2.14 & 1.75 & 1.4 \\
\hline \multicolumn{7}{|l|}{ RC } \\
\hline MB11 & .69 & .27 & .06 & .03 & .16 & .15 \\
\hline MB12 & .77 & -.02 & .02 & .13 & -.05 & .13 \\
\hline MB13 & .75 & .12 & .23 & .09 & .21 & -.27 \\
\hline MB14 & .63 & .31 & .13 & .17 & -.10 & -.15 \\
\hline \multicolumn{7}{|l|}{ CI } \\
\hline MB21 & .03 & .71 & .16 & .30 & .17 & -.02 \\
\hline MB22 & -.06 & .81 & .03 & .05 & -.04 & .01 \\
\hline MB23 & .33 & .68 & -.10 & -.10 & .04 & .02 \\
\hline \multicolumn{7}{|l|}{ MF } \\
\hline MB31 & .11 & -.06 & .72 & .01 & -.08 & -.07 \\
\hline MB32 & .23 & .31 & .89 & .03 & .06 & -.21 \\
\hline MB33 & .15 & .11 & .82 & -.19 & .09 & -.12 \\
\hline \multicolumn{7}{|l|}{ MC } \\
\hline MB41 & .18 & .31 & .08 & .58 & .17 & -.18 \\
\hline MB42 & -.04 & .17 & .20 & .57 & .02 & -.04 \\
\hline MB43 & -.02 & -.12 & .18 & .52 & .23 & .25 \\
\hline MB44 & -.10 & -.17 & .04 & .73 & .19 & .07 \\
\hline \multicolumn{7}{|l|}{ SC } \\
\hline MB51 & .11 & .28 & .13 & .17 & .76 & .09 \\
\hline MB52 & .03 & .12 & .02 & -.13 & .83 & -.06 \\
\hline MB53 & .09 & .22 & .15 & -.14 & .70 & .25 \\
\hline \multicolumn{7}{|l|}{ RE } \\
\hline MB61 & -.05 & .16 & .25 & .05 & -.36 & .87 \\
\hline MB62 & .06 & .16 & .01 & .03 & -.04 & .83 \\
\hline MB63 & -.01 & -.06 & -.08 & -.14 & .08 & .75 \\
\hline MB64 & .17 & .03 & -.22 & .30 & -.15 & .78 \\
\hline MB65 & .22 & -.12 & -.10 & .06 & .13 & .54 \\
\hline MB66 & .06 & .09 & -.16 & .06 & .17 & .64 \\
\hline
\end{tabular}


Aladwani and palvia (2002) suggested that cut-offs should be based on the purpose for which the instrument is meant for. Thus, the loadings suggest that the items belong accordingly to their groups. In all the factor analyses conducted, every scale's item converged impressively on the same factor representing it. Thus, convergent validity is also established which means all the measures converge according to their intended purpose of measurement
(Aladwani and palvia, 2002). In other words, convergent validity implies that elements from different sources obtained in various ways point to the same meaning for a construct. In an exploratory factor analysis, a factor is considered to possess convergent validity if its eigenvalue exceeds 1.0 and in addition, all the factor loadings should exceed the minimum value of 0.30 (Chen and Paulraj, 2004; Hair et al, 1995).

Table 3. Principal Factor Analysis (Forward Chain- Applicability)

\begin{tabular}{|c|c|c|c|c|c|c|c|c|c|c|}
\hline & \multicolumn{10}{|c|}{ Factors } \\
\hline & F 1 & F 2 & F3 & F4 & F5 & F6 & F7 & F8 & F9 & F10 \\
\hline$\%$ Variance & 14.68 & 10.89 & 10.49 & 7.70 & 5.91 & 5.29 & 4.49 & 4.17 & 3.66 & 3.16 \\
\hline Eigenvalue & 7.49 & 5.56 & 5.38 & 3.93 & 3.01 & 2.70 & 2.49 & 1.79 & 1.39 & 1.18 \\
\hline \multicolumn{11}{|l|}{ GC } \\
\hline MF11 & .53 & .20 & .18 & .09 & -.15 & .06 & .10 & .16 & .06 & -.14 \\
\hline MF12 & .66 & .25 & -.25 & .11 & .05 & -.18 & .29 & -.21 & .02 & .24 \\
\hline MF13 & .58 & .15 & .10 & -.15 & .23 & .04 & .06 & .14 & .14 & -.16 \\
\hline MF14 & .56 & -.11 & .18 & .13 & .15 & .21 & .04 & .30 & -.02 & .01 \\
\hline \multicolumn{11}{|l|}{$\mathbf{C P}$} \\
\hline MF21 & .22 & .59 & .19 & -.19 & .04 & .26 & -.27 & .06 & .20 & -.20 \\
\hline MF22 & .11 & .76 & .20 & .06 & -.04 & .13 & .02 & .29 & .11 & .06 \\
\hline MF23 & -.07 & .65 & -.15 & .15 & .26 & -.32 & .16 & .03 & .04 & .16 \\
\hline \multicolumn{11}{|l|}{ LPM } \\
\hline MF31 & .22 & -.27 & .64 & -.22 & .05 & .12 & -.24 & .25 & -.11 & -.21 \\
\hline MF32 & -.05 & .14 & .72 & .10 & .01 & .22 & .29 & .08 & .22 & .06 \\
\hline MF33 & .06 & -.10 & .63 & -.12 & .13 & -.00 & .23 & .01 & -.25 & -.07 \\
\hline MF34 & .23 & -.11 & .58 & -.03 & .19 & .06 & .04 & .14 & -.23 & -.06 \\
\hline MF35 & .17 & .22 & .49 & .13 & .14 & .12 & .25 & .18 & -.01 & -.20 \\
\hline \multicolumn{11}{|l|}{ PC } \\
\hline MF41 & .20 & -.00 & .28 & .49 & .17 & .18 & .29 & .16 & .13 & .23 \\
\hline MF42 & .10 & -.06 & .10 & .65 & -.00 & .25 & .24 & .01 & .07 & .10 \\
\hline MF43 & .24 & .20 & .07 & .53 & .31 & .23 & .13 & .18 & .15 & -.01 \\
\hline MF44 & -.08 & -.10 & .18 & .58 & .05 & .06 & .19 & -.09 & .26 & -.06 \\
\hline MF45 & -.19 & .02 & -.11 & .73 & -.18 & -.25 & -.23 & .03 & -.06 & -.18 \\
\hline MF46 & .14 & .05 & .29 & .51 & .10 & -.05 & -.08 & .12 & -.20 & .11 \\
\hline \multicolumn{11}{|l|}{ MC } \\
\hline MF51 & .34 & -.06 & .22 & .25 & .61 & .15 & -.09 & .28 & .09 & .07 \\
\hline MF52 & .06 & -.20 & -.12 & .09 & .53 & -.26 & -.02 & .16 & -.22 & .01 \\
\hline MF53 & .23 & -.20 & .26 & .15 & .68 & -.12 & .05 & .13 & -.09 & .17 \\
\hline MF54 & .15 & .01 & .18 & .19 & .74 & .20 & .24 & .23 & .13 & .29 \\
\hline MF55 & .14 & .15 & -.02 & .25 & .51 & .11 & .13 & .23 & -.04 & -.07 \\
\hline MF56 & .16 & .03 & .17 & -.09 & .52 & .00 & .27 & .25 & .15 & .10 \\
\hline MF57 & .25 & .20 & .10 & -.15 & .63 & -.30 & .18 & .06 & .01 & -.21 \\
\hline MF58 & .16 & .19 & .16 & .00 & .72 & .30 & .20 & .10 & .04 & .13 \\
\hline \multicolumn{11}{|l|}{ SC } \\
\hline MF61 & .01 & -.20 & .03 & -.08 & .34 & .60 & -.17 & .09 & .09 & .32 \\
\hline MF62 & .06 & .19 & -.01 & -.11 & -.30 & .60 & .25 & -.22 & .19 & -.30 \\
\hline MF63 & -.04 & -.07 & -.04 & .21 & -.04 & .51 & -.05 & .10 & -.10 & -.08 \\
\hline MF64 & -.25 & .01 & -.01 & -.08 & -.23 & .50 & -.16 & -.02 & -.14 & .02 \\
\hline MF65 & .16 & -.10 & .22 & .00 & .18 & .59 & -.33 & -.10 & -.01 & .21 \\
\hline TSCC & & & & & & & & & & \\
\hline
\end{tabular}




\begin{tabular}{|c|c|c|c|c|c|c|c|c|c|c|}
\hline MF71 & .10 & .08 & -.02 & .02 & -.01 & -.21 & .58 & .08 & .16 & -.03 \\
\hline MF72 & .27 & .16 & .30 & .26 & .11 & .23 & .66 & .26 & .18 & .21 \\
\hline MF73 & .16 & .02 & .24 & .05 & .12 & .28 & .46 & .11 & .29 & .29 \\
\hline MF74 & .22 & -.21 & -.16 & .08 & .12 & .05 & .74 & -.07 & -.22 & -.06 \\
\hline MF75 & .12 & .14 & .15 & -.03 & .18 & .24 & .50 & .02 & .22 & .16 \\
\hline \multicolumn{11}{|l|}{ RESP } \\
\hline MF81 & .19 & -.17 & .25 & .20 & .08 & .15 & .05 & .62 & -.03 & .22 \\
\hline MF82 & -.05 & -.21 & .15 & .25 & -.01 & .03 & -.17 & .54 & .14 & -.13 \\
\hline MF83 & -.09 & -.05 & .12 & -.00 & -.04 & -.06 & -.20 & .75 & .05 & .07 \\
\hline MF84 & -.17 & .13 & -.26 & -.07 & -.16 & .07 & -.26 & .56 & -.21 & -.16 \\
\hline MF85 & -.26 & -.07 & .00 & .10 & -.23 & -.18 & -.27 & .59 & .16 & .16 \\
\hline \multicolumn{11}{|l|}{ QUAL } \\
\hline MF91 & .06 & -.12 & .20 & .14 & -.02 & .20 & .28 & .12 & .63 & .12 \\
\hline MF92 & .12 & -.20 & .10 & .02 & .17 & .14 & .18 & .17 & .46 & .06 \\
\hline MF93 & .05 & .09 & .28 & .12 & .03 & .25 & -.21 & .03 & .50 & .00 \\
\hline MF94 & -.05 & -.01 & -.00 & -.21 & .22 & -.08 & .00 & .04 & .49 & .10 \\
\hline \multicolumn{11}{|l|}{ FLEX } \\
\hline MF101 & -.03 & .01 & .15 & .29 & .05 & .09 & -.09 & .25 & -.02 & .58 \\
\hline MF102 & .21 & -.09 & .21 & .26 & -.06 & .12 & .19 & .19 & .14 & .55 \\
\hline MF103 & -.07 & -.25 & .13 & -.06 & .09 & -.18 & -.05 & .19 & .16 & .50 \\
\hline MF104 & .14 & .04 & .21 & .29 & .03 & .13 & .06 & .29 & -.02 & .46 \\
\hline
\end{tabular}

Table 4.Principal Factor Analysis (Reverse Chain-Applicability)

\begin{tabular}{|c|c|c|c|c|c|c|}
\hline & \multicolumn{6}{|c|}{ Factors } \\
\hline & F1 & $\mathrm{F} 2$ & F3 & $\mathrm{F} 4$ & F5 & F6 \\
\hline$\%$ Variance & 16.3 & 11.8 & 10.8 & 8.2 & 7.3 & 6.13 \\
\hline Eigenvalue & 3.76 & 2.71 & 2.49 & 1.88 & 1.68 & 1.25 \\
\hline \multicolumn{7}{|l|}{ RC } \\
\hline MB11 & -.48 & .07 & .06 & .08 & .15 & .14 \\
\hline MB12 & .51 & -.16 & .09 & -.23 & -.15 & -.13 \\
\hline MB13 & .74 & -.03 & .07 & .24 & .05 & .02 \\
\hline MB14 & .18 & .03 & -.01 & -.25 & .07 & .17 \\
\hline \multicolumn{7}{|l|}{ CI } \\
\hline MB21 & -.11 & .77 & -.11 & -.08 & -.10 & .07 \\
\hline MB22 & .08 & .60 & .17 & .06 & .29 & -.13 \\
\hline MB23 & .14 & .65 & .15 & .27 & .14 & .21 \\
\hline \multicolumn{7}{|l|}{ MF } \\
\hline MB31 & .05 & -.11 & .76 & -.06 & -.10 & .16 \\
\hline MB32 & .09 & .08 & .55 & .03 & -.07 & .05 \\
\hline MB33 & .10 & .19 & .56 & .24 & .23 & .17 \\
\hline \multicolumn{7}{|l|}{ MC } \\
\hline MB41 & .141 & -.09 & .02 & .04 & .71 & .17 \\
\hline MB42 & .24 & .21 & .01 & -.00 & .76 & -.12 \\
\hline MB43 & .18 & .08 & .08 & -.21 & .73 & .03 \\
\hline MB44 & -.02 & -.04 & -.05 & .00 & .79 & -.10 \\
\hline \multicolumn{7}{|l|}{ SC } \\
\hline MB51 & .18 & .08 & .28 & .55 & -.31 & -.13 \\
\hline MB52 & .00 & .08 & -.10 & .86 & .13 & -.02 \\
\hline MB53 & .21 & .26 & .29 & .77 & .30 & -.20 \\
\hline \multicolumn{7}{|l|}{ RE } \\
\hline MB61 & .29 & .02 & .05 & .02 & -.31 & .60 \\
\hline MB62 & .28 & -.08 & -.28 & .18 & -.10 & .55 \\
\hline MB63 & .05 & .38 & .37 & .10 & .02 & .60 \\
\hline MB64 & -.09 & -.08 & .04 & -.13 & .27 & .61 \\
\hline MB65 & -.09 & -.16 & .05 & .24 & -.06 & .71 \\
\hline MB66 & .32 & .01 & .12. & -.25 & .14 &. .52 \\
\hline
\end{tabular}




\section{Confirmatory Factor Analysis}

Confirmatory factor analysis was further carried out using Lisrel 8.8 software. This was aimed at confirming the discriminant validity and unidimensionality of the factors. Brown (2006) and Yang et al (2005) expounded that discriminant validity is used to show that a measure can be differentiated from other measures which may be similar. In other words, it is applied to evaluate the level to which the individual items of a construct are unique and do not measure other constructs (Chen and Paulraj, 2004). To establish the discriminant validity for the factors, models were built for all the possible pairs of measures (latent constructs). The models were run under two conditions as specified in (Chen and Paulraj, 2004; Yang et al, 2005). The first condition was allowing a free correlation between the two measures while the second was fixing the correlation to unity. A total of 45 different discriminant validity evaluations were conducted for the forward chain measures, while the reverse chain measures had a total of 15. Based on the results obtained as presented in Tables $5,6,7$ and 8, a significant difference existed between the $\chi^{2}$ values of all the two models at $\mathrm{P}<0.01$ confidence level. This implies that there is a significant distinction between any two measures. This provides a strong evidence of discriminant validity amongst the measures in terms of their importance and applicability (Chen and Paulraj, 2004; Nahm et al, 2003).

Unidimensionality was also tested using Lisrel 8.8. The test was conducted to ensure that the assessment measures only one construct and how reliable it does that (Yang et al, 2005). Three different models were used to conduct the test for the forward chain and two models were utilized for the reverse chain. This was due to the fact that building a single model for each chain did not converge on the software. As a result, 3 models (ie. GC-LPMPC-MC, SC-CP and TSCC-RESP-FLEX-QUAL) were built for the forward chain. On the other hand, 2 models (RC-MF-MC-RE and SC-CI) were built for the reverse chain. There are two basic conditions necessary for establishing unidimensionality and these are: an empirical metric should be significantly associated with the empirical representation of a measure and it should be associated with only one measure (Hair et al, 1995; Chen and Paulraj, 2004).

Unidimensionality was evaluated using model fit indices. The results of the evaluation of all the models for the forward chain and reverse chain are presented in Table 9. The first is the Chi square value $\left(\chi^{2}\right)$ which determines the goodness of fit measure with respect to the overall model. The null hypothesis implies that the predicted covariance matrix is same as the observed sample matrix, that is $\varepsilon=S$. A small value of $\chi^{2}$ and failure to reject the null hypothesis is a sign of a good fit model. A higher number though, may render the $\chi^{2}$ problematic and thus lead to misleading result. Thus, an alternative approach of $\chi^{2} / \mathrm{DF}$ is used in which values between 3 and 5 signify close-fit models (Carter and Wu, 2010).

Other criteria for model fitness are adjusted goodness of fit index (AGFI), goodness of fit index (GFI), Bentler and Bonnet nonnormed fit index (NNFI), Bentler and Bonnet normed fit index (NFI), and Bentler comparative fit index (CFI) (Chen and Paulraj, 2004; Joreskog and Sorbom, 1999). NFI and NNFI are used to test the incremental fit of a model (Kline, 2005). These indices compare the model against an independent model that assumes variables are uncorrelated ( $\mathrm{Hu}$ and Bentler, 1999). CFI evaluates the fit of a user specified solution in relation to a more restricted model in which the covariances between the indicators are fixed to zero (Kline, 2005).

It has been stated that GFI and AGFI are used to test the absolute fit of models ( $\mathrm{Hu}$ and Bentler, 1999). It was further explained that GFI estimates the proportion of variance in the sample matrix explained by the model and a minimum of 0.9 indicates a good fit. Models which have AGFI index greater than 0.80, NNFI, NFI and CFI indices greater than 0.90 are considered close-fit (Chen and Paulraj, 2004). Thus, an index value of 0 implies a poor fit and as the 
value approaches 1 , the model fit becomes better.

It is an established fact that root mean square error of approximation (RMSEA) and standardized root mean square residual (SRMR) are also measures for model fitness. These indices are used to evaluate if there are discrepancies between observed covariance residuals of a model (Carter and $\mathrm{Wu}, 2010$ ). SRMR values less than 0.08 and RMSEA values less than 0.06 imply very good models (Brown, 2006; Hu and Bentler, 1999).

\section{Multiple Regression Analysis}

In this study, criterion validity was evaluated using multiple linear regression analysis. Multiple regressions analysis is a statistical technique which allows the prediction of score on a given variable based on scores on several other variables (Field, 2009). In other words, it attempts to assess the relationship between a dependent variable and two or more independent variables. Furthermore, this technique explores the linear relationships between the predictor and criterion variables. In a multiple regression analysis, various criteria are used to analyze the relationships. First is the Standardized Regression Coefficient ( $\beta$ ) which is a measure of how strongly each predictor variable influences the criterion variable (Field, 2009). Therefore, the higher the beta value, the greater the impact of the predictor variable on the criterion variable. The second is the $R$ value which is a measure of the correlation between the observed value and the predicted value of the criterion variable. The third is the $R$ Square $\left(R^{2}\right)$ value, which is the square of the measure of correlation and it indicates the proportion of the variance in the criterion variable which is accounted for by the model (Field, 2009). It was further stated that the $\mathrm{R}^{2}$ value seems to over-estimate the success of a model when applied to the real world, therefore the Adjusted $\mathrm{R}^{2}$ value is calculated which takes into account the number of variables in the model and the number of observations the model is based on. In addition, the Adjusted $\mathrm{R}^{2}$ value gives the most useful measure of the success of a model (Field, 2009).

Table 5. Discriminant Validity Test for Forward Chain Measures (Importance)

\begin{tabular}{|c|c|c|c|c|c|c|c|c|c|c|}
\hline Measures & GC & $\mathrm{CP}$ & LPM & PC & MC & SC & TSCC & RESP & QUAL & FLEX \\
\hline GC & - & & & & & & & & & \\
\hline $\mathrm{CP}$ & 98.27 & - & & & & & & & & \\
\hline LPM & 80.50 & 204.17 & - & & & & & & & \\
\hline PC & 96.63 & 231.53 & 74.58 & - & & & & & & \\
\hline $\mathrm{MC}$ & 91.30 & 228.71 & 305.27 & 97.21 & - & & & & & \\
\hline SC & 90.80 & 190.20 & 109.45 & 81.03 & 35.21 & - & & & & \\
\hline TSCC & 114.37 & 216.47 & 142.75 & 56.61 & 83.44 & 304.75 & - & & & \\
\hline RESP & 81.43 & 203.93 & 284.93 & 111.67 & 106.38 & 200.53 & 460.82 & - & & \\
\hline QUAL & 76.62 & 127.11 & 91.55 & 86.92 & 198.58 & 381.46 & 396.01 & 216.44 & - & \\
\hline FLEX & 80.91 & 277.62 & 316.98 & 206.52 & 284.32 & 360.79 & 507.22 & 391.20 & 417.92 & - \\
\hline
\end{tabular}

From this study all the $\chi^{2}$ differences were significant at the 0.01 level 
Table 6. Discriminant Validity Test for forward chain Measures (Applicability)

\begin{tabular}{|c|c|c|c|c|c|c|c|c|c|c|}
\hline Measures & $\mathrm{GC}$ & $\mathrm{CP}$ & LPM & $\mathrm{PC}$ & $\mathrm{MC}$ & SC & TSCC & RESP & QUAL & FLEX \\
\hline GC & - & & & & & & & & & \\
\hline $\mathrm{CP}$ & 52.09 & - & & & & & & & & \\
\hline LPM & 40.11 & 114.28 & - & & & & & & & \\
\hline $\mathrm{PC}$ & 65.38 & 105.96 & 191.20 & - & & & & & & \\
\hline $\mathrm{MC}$ & 36.67 & 132.55 & 148.09 & 103.59 & - & & & & & \\
\hline SC & 48.69 & 108.01 & 204.29 & 90.11 & 207.35 & - & & & & \\
\hline TSCC & 52.07 & 147.35 & 136.03 & 115.91 & 246.04 & 116.61 & - & & & \\
\hline RESP & 63.90 & 129.67 & 142.08 & 96.29 & 201.90 & 184.32 & 56.36 & - & & \\
\hline QUAL & 58.37 & 150.31 & 185.76 & 62.06 & 233.28 & 204.05 & 89.20 & 198.59 & - & \\
\hline FLEX & 40.10 & 133.97 & 141.58 & 80.48 & 204.57 & 281.40 & 77.16 & 203.47 & 256.03 & - \\
\hline
\end{tabular}

From this study all the $\chi^{2}$ differences were significant at the 0.01 level

Lastly, the significance of the model (P) and that of the predictor variables (p) are also used. The $\mathrm{p}$ values give a rough indication of the impact of each predictor variable, where a small $p$ value suggests that a predictor variable is having a large impact on the criterion variable (Field, 2009).

In the analysis, the average scores for each of the measures were used as the independent variables and the result of the final question of the questionnaire that asked whether all the appropriate measures for green supply chain performance measurement have been covered was used as the dependent variable. The result of this question was quantified, where 'YES' was given 1 and 'NO' was assigned 0 . The SPSS multiple regression option was set to 'exclude cases list-wise', therefore SPSS analyzed the data using only cases with no missing value. From the results, it can be seen that the criterion validity of all the measures is established (forward chain: $\mathrm{F}_{10}=68.115$; $\mathrm{P}<0.05$; Adjusted $\mathrm{R}^{2}=0.713$, reverse chain: $\mathrm{F}_{6}=50.73 ; \mathrm{P}<0.05 ;$ Adjusted $\mathrm{R}^{2}=0.825$, and all the variables are significant).

Table 7. Discriminant Validity Test for Reverse Chain Measures (Importance)

\begin{tabular}{|c|c|c|c|c|c|c|}
\hline Measures & $\mathrm{RC}$ & $\mathrm{CI}$ & MF & MC & $\mathrm{SC}$ & $\mathrm{RE}$ \\
\hline $\mathrm{RC}$ & - & & & & & \\
\hline CI & 303.67 & - & & & & \\
\hline MF & 499.25 & 581.03 & - & & & \\
\hline $\mathrm{MC}$ & 601.04 & 427.55 & 152.50 & - & & \\
\hline SC & 591.17 & 302.47 & 138.77 & 59.26 & - & \\
\hline $\mathrm{RE}$ & 204.11 & 483.29 & 147.82 & 104.29 & 213.48 & - \\
\hline
\end{tabular}

From this study all the $\chi^{2}$ differences were significant at the 0.01 level

Table 8. Discriminant Validity Test for Reverse Chain Measures (Applicability)

\begin{tabular}{|c|c|c|c|c|c|c|}
\hline Measures & $\mathrm{RC}$ & $\mathrm{CI}$ & MF & MC & $\mathrm{SC}$ & $\mathrm{RE}$ \\
\hline $\mathrm{RC}$ & - & & & & & \\
\hline $\mathrm{CI}$ & 153.02 & - & & & & \\
\hline MF & 138.96 & 65.18 & - & & & \\
\hline MC & 182.47 & 79.32 & 112.90 & - & & \\
\hline SC & 125.64 & 58.08 & 131.48 & 51.01 & - & \\
\hline $\mathrm{RE}$ & 132.28 & 72.41 & 164.16 & 42.63 & 173.85 & - \\
\hline
\end{tabular}

From this study all the $\chi^{2}$ differences were significant at the 0.01 level 
Table 9. Model Fitness Indices

\begin{tabular}{|l|l|l|l|l|l|l|l|l|l|l|}
\hline \multicolumn{10}{|c|}{ Forward Chain Models } \\
\hline Model & $\boldsymbol{\chi}^{\mathbf{2}}$ & $\mathbf{d f}$ & $\boldsymbol{\chi}^{\mathbf{2}} / \mathbf{d f}$ & $\mathbf{N F I}$ & $\mathbf{N N F I}$ & $\mathbf{C F I}$ & GFI & AGFI & SRMR & RMSEA \\
\hline GC-LPM-PC-MC & 120.68 & 26 & 4.64 & 0.90 & 0.92 & 0.97 & 0.92 & 0.86 & 0.06 & 0.04 \\
\hline SC-CP & 62.55 & 19 & 3.29 & 0.90 & 0.91 & 0.92 & 0.92 & 0.81 & 0.05 & 0.05 \\
\hline TSCC-RESP-FLEX-QUAL & 191.75 & 54 & 3.55 & 0.96 & 0.95 & 0.92 & 0.90 & 0.84 & 0.06 & 0.046 \\
\hline \multicolumn{10}{|c|}{ Reverse Chain Models } \\
\hline RC-MF-MC-RE & 190.25 & 42 & 4.53 & 0.96 & 0.93 & 0.97 & 0.95 & 0.91 & 0.04 & 0.048 \\
\hline SC-CI & 136.57 & 33 & 4.54 & 0.90 & 0.91 & 0.90 & 0.93 & 0.88 & 0.06 & 0.02 \\
\hline
\end{tabular}

\section{Conclusions and Recommendations}

This study looked at the validation of measures and metrics for green supply chain performance measurement. The validation involved construct validity test using principal factor analysis with varimax rotation, while confirmatory factor analysis was used to assess the discriminant validity and unidimensionality. Multiple regression analysis was conducted to test the criterion validity of the measures. From the results of the tests, it was observed that the measures and their metrics are valid.

It is recommended that a study should be conducted to extend these measures and their metrics to the performance measurement of other industries' green supply chains such as food, electronics, etc. Furthermore, case studies should be conducted in real industries to observe how applicable these measures and metrics could be in the actual performance evaluation of a green supply chain. Finally, effort should be made at standardizing the metrics in terms of quantity and quality as the case may be.

\section{Acknowledgments}

The authors would like to thank Universiti Teknologi Malaysia for the support given. Our gratitude also goes to all the respondents for making out time amidst their tight schedule to complete the survey questionnaire for this research work.

\section{References}

Aladwani, A. M. \& Palvia, P. C. (2002). "Developing and validating An Instrument For Measuring User Perceived Web
Quality," Information and Management, 39(1). 467- 476.

Beamon, B. M. (1999). "Designing the Green Supply Chain," Logistics Information Management,12(4). 332-342.

Brown, T. A. (2006). Confirmatory Factor Analysis for Applied Research, Guilford Press, New York.

Carter, S. A. \& Wu, K. D. (2010). "Symptoms of Specific and Generalized Social Phobia: An Examination of Discriminant Validity and Structural Relations with Mood and Anxiety Symptoms," Behavior Therapy, 41(2). 254-265.

Chen, I. J. \& Paulraj, A. (2004). "Towards a Theory of Supply Chain Management: The Constructs and Measurements," Journal of Operations Management, 22(2). 119-150.

Field, A.P. (2009). Discovering Statistics Using SPSS: and Sex and Drugs and Rock "n" Roll, Sage, London.

Green, K., Morton, B. \& New, B. (1998). "Green Purchasing and Supply Policies: Do They Improve Companies' Environmental Performance?," Supply Chain Management: An International Journal. 3(2). 89-95.

Gunasekaran, A, Patel, C. \& Tirtiroglu, E. (2001). "Performance Measures and Metrics in a Supply Chain Environment," International Journal of Operations and Production Management, 21(1/2). 71-87.

Hair, J. F., Anderson, R. E., Tatham, R. L. \& Black, W.C. (1995). Multivariate Data Analysis with Readings, Prentice Hall, Englewood Cliffs, New Jersey. 
Hervani, A. A., Helms, M. M. \& Sarkis, J. (2005). "Performance Measurement for Green Supply Chain Management," Benchmarking: An International Journal,12(4). 330-353.

Hu, L. \& Bentler, P. M. (1999). "Cutoff Criteria for Fit Indices in Covariance Structure Analysis: Conventional Criteria Versus New Alternatives," Structural Equation Modeling: A Multidisciplinary Journal, 6(1). 1-55.

Joreskog, K.G. \& Sorbom, D. (1999). 'LISREL 8: User's Reference Guide,' Scientific Software Inc. Chicago.

Kline, R. B. (2005). "Principles and Practice of Structural Equation Modeling," Guilford, New York.

Krajnc, D., Mele M. \& Glavi, P. (2007). "Fuzzy Logic Model for the Performance Benchmarking of Sugar Plants by Considering Best Available Techniques," Resources, Conservation and Recycling, 52(2). 314-330.

Lai, K.-H., Ngai, E. W. T. \& Cheng, T. C. E. (2002). "Measures for Evaluating Supply Chain Performance in Transport Logistics," Transportation Research Part E: Logistics and Transportation Review, 38(6). 439-456.

Liang, L., Yang F., Cook W. D. \& Zhu J. (2006). "DEA Models for Supply Chain Efficiency Evaluation," Annals of Operations Research, 145(1). 35-49.

Linton, J. D., Klassen R. \& Jayaraman V. (2007). "Sustainable Supply Chains: An Introduction," Journal of Operations Management (25:1). 1075-1082.

Morgan, C. (2004). "Structure, Speed And Salience: Performance Measurement in the Supply Chain," Business Process Management Journal, 10(5). 522-536.

Nahm, A.Y., Vonderembse, M. A. \& Koufteros, X. A., (2003). "The Impact of Organizational Structure on Time-Based Manufacturing and Plant Performance," Journal of Operations Management. 21(3). 281-306.
Neely, A. Gregory, M. \& Platts, K. (2005). "Performance Measurement System Design: A Literature Review and Research Agenda," International Journal of Operations and Production Management, 25(12). 1228-1263.

Olugu, E.U., Wong, K.Y. \& Shaharoun, A. M. (2010b). "A Comprehensive Approach in Assessing the Performance of an Automobile Closed-Loop Supply Chain," Sustainability, 2(4). 871-889.

Olugu, E.U., Wong, K.Y. \& Shaharoun, A. M. (2011). "Development of Key Performance Measures for the Automobile Green Supply Chain," Resources, Conservation and Recycling, 55(6). 567-579.

Rao, P. \& Holt, D. (2005). "Do Green Supply Chains Lead to Competitiveness and Economic Performance?," International Journal of Operations and Production Management, 25(9). 898-916.

Sarkis, J. (2003). "A Strategic Decision Framework for Green Supply Chain Management," Journal of Cleaner Production, 11(4). 397-409.

Schultmann, F., Zumkeller, M. \& Rentz, O. (2004). "Integrating Spent Products Material into Supply Chains: The Recycling of End-of-Life-Vehicles as an Example," Supply Chain Management and Reverse Logistics, Dyckhoff, H, Lackes, R. and Reese, J. (eds). Springer-Verlag, Berlin, 35-59.

Stewart, G. (1995). "Supply Chain Performance Benchmarking Study Reveals Keys to Supply Chain Excellence," Logistics Information Management, 8(2). 38-44.

Turnbull, P., Oliver, N. \& Wilkinson, B. (1992). "Buyer-supplier Relations in the UK Automotive Industry: Strategic Implications of the Japanese Manufacturing Model," Strategic Management Journal, 13(1). 159-168.

Vachon, S. \& Klassen, R. D. (2008). "Environmental Management and Manufacturing Performance: The Role of Collaboration in the Supply Chain," 
International Journal of Production Economics, 111(2). 299-315.

Wycherley, I. (1999). "Greening Supply Chains: The Case of the Body Shop International," Business Strategy and the Environment, 8(2). 120-127.

Yang, Z, Cai, S., Zhou, Z. \& Zhou, N. (2005). "Development and Validation of an Instrument to Measure User Perceived Service Quality of Information Presenting Web Portals," Information and Management 42(4). 575-589.

Zhu, Q. \& Sarkis, J. (2004). "Relationships between Operational Practices and Performance among Early Adopters of Green Supply Chain Management Practices in Chinese Manufacturing Enterprises," Journal of Operations Management, 22(3). 265-289.

Zhu, Q. \& Sarkis, J. (2006). "An InterSectoral Comparison of Green Supply Chain Management in China: Drivers and Practices," Journal of Cleaner Production,14(5). 472-486. 